\title{
Status of the Production of the LHC Superconducting Corrector Magnets
}

\author{
M. Allitt, A. Ijspeert, M. Karppinen, J. Mazet, and R. Wolf
}

\begin{abstract}
The Large Hadron Collider (LHC) will be equipped with a large number $(\mathbf{6 4 0 0})$ of superconducting corrector magnets. These magnets are powerful, with typical peak fields of 3-4 T on the coils, but at the same time compact and of low cost. There are many types: sextupoles, octupoles and decapoles to correct the main dipole field, dipoles, quadrupoles, sextupoles and octupoles to condition the proton beams and several nested correctors from dipole to dodecapole in the inner triplets. The sizes vary from $6 \mathrm{~kg}$, $110 \mathrm{~mm}$ long, nested decapole-octupole spool pieces to $1800 \mathrm{~kg}$, $1.4 \mathrm{~m}$ long, trim quadrupoles.

THE fabrication of the 11 different types of magnets is assured by 10 contracts placed at 6 firms, two of which are in India. A number of magnets are now in series production, others in their pre-series production. The paper describes the present state of the fabrication and the testing of these magnets.
\end{abstract}

Index Terms-Correctors, LHC, magnets, superconducting.

\section{LHC CORRECTOR MAGNET OVERVIEW}

$\mathbf{T}$ 7 HE Large Hadron Collider (LHC) will be equipped with more than 6400 corrector magnets (Fig. 1 shows two examples). About 3800 single aperture and 1000 twin aperture corrector magnets will be used. The $194 \mathrm{~mm}$ beam separation gives sufficient lateral space to build all correctors as single bore modules, with a nominal working point between $40-60 \%$ along the load line. Twin aperture units are assembled by keying corresponding modules into laminated support structures. The assembly by keying insures mechanical precision and allows flexibility during mounting, since the same type of module is used for a normal or for a skew magnet. To optimize the cost of the corrector magnets, common design and fabrication principles [1]-[3], [14] are applied:

- Use of flat multi-wire cable ribbon to reduce the number of winding turns of a coil.

- Counter-rotating winding for automation of coil fabrication and suppression of layer jumps and spacers.

- Coil impregnation by wet wrapping of epoxy. Vacuum impregnation is used only for the larger magnets.

- Enhancement of the field using so-called scissors laminations [3], [14] placed close to the coils, made of magnetic material and which transfer the pre-stress.

- Pre-stress applied by shrinking rings avoiding the use of a press.

- Multipole correctors of higher order than the sextupole, i.e., octupole, decapole and dodecapole, are built with half the number of coils, which is more economical and easier

Manuscript received October 20, 2003.

The authors are with the Accelerator Technology Division, CERN, 1211

Geneva 23, Switzerland (e-mail: Rob.Wolf@cern.ch).

Digital Object Identifier 10.1109/TASC.2004.829045

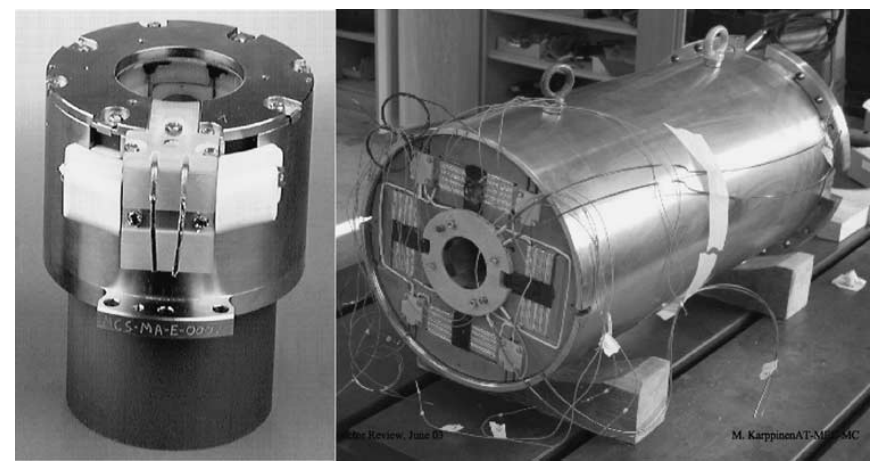

Fig. 1. A small $(15 \mathrm{~cm})$ MCS corrector (left) and the much larger $(70 \mathrm{~cm})$ nested horizontal and vertical orbit corrector MCBX.

TABLE I

OVERVIEW OF CORRECTOR MAGNET TYPES AND LOCATION

\begin{tabular}{|c|c|c|}
\hline Name & Description & Location \\
\hline MCS & Sextupole multipole corrector & Main MBA \& MBB dipoles \\
\hline MCDO & $\begin{array}{l}\text { Nested Decapole-Octupole } \\
\text { multipole corrector }\end{array}$ & Main MBA dipoles \\
\hline MSCB & $\begin{array}{l}\text { Sextupole-Dipole Corrector } \\
\text { (lattice chromaticity \& orbit). } \\
\text { Exists in } 4 \text { variants with all } \\
\text { combinations of normal \& } \\
\text { skew fields. }\end{array}$ & $\begin{array}{l}\text { 1. Main quadrupoles (Short } \\
\text { Straight Sections), } \\
\text { 2. dispersion suppressors }\end{array}$ \\
\hline $\begin{array}{l}\text { MQT, } \\
\text { MQS }\end{array}$ & Tuning and Skew Quadrupoles & $\begin{array}{l}\text { Main quadrupoles (Short } \\
\text { Straight Sections) }\end{array}$ \\
\hline MO & $\begin{array}{l}\text { Octupole Lattice Corrector } \\
\text { (Landau damping) }\end{array}$ & $\begin{array}{l}\text { Main quadrupoles (Short } \\
\text { Straight Sections) }\end{array}$ \\
\hline $\begin{array}{l}\text { MCBC, } \\
\text { MCBY }\end{array}$ & Dipole correctors (orbit) & $\begin{array}{l}\text { Insertion region and dispersion } \\
\text { suppressors }\end{array}$ \\
\hline MQTL & Long Trim Quadrupole & $\begin{array}{l}\text { Insertion region and dispersion } \\
\text { suppressors }\end{array}$ \\
\hline MCBX & $\begin{array}{l}\text { Nested Horizontal \& Vertical } \\
\text { Dipole Orbit corrector. }\end{array}$ & Inner Triplets \\
\hline MCBXA & $\begin{array}{l}\text { MCBX with a nested 6-pole, } \\
12 \text { pole multipole corrector } \\
\text { insert (MCSTX) }\end{array}$ & \\
\hline MQSX & $\begin{array}{l}\text { Skew quadrupole (formerly } \\
\text { part of MQSXA) }\end{array}$ & Inner Triplets \\
\hline MCSOX & $\begin{array}{l}\text { Nested skew sextupole, } \\
\text { octupole, skew octupole } \\
\text { (formerly part of MQSXA) }\end{array}$ & Inner Triplets \\
\hline
\end{tabular}

to wind. This produces small asymmetries in the ends, which give only a small, acceptable, field error.

Quench protection [4], [5] for series connected magnets is provided by parallel resistors combined with energy extraction systems.

\section{CORRECTOR TYPES AND CIRCUITS}

We distinguish several types of correctors for LHC. 
TABLE II

SHORT SUMMARY OF CORRECTOR MAGNET PARAMETERS

\begin{tabular}{|c|c|c|c|c|c|c|c|c|c|c|}
\hline Magnet & Yoke & $\begin{array}{c}\text { Aperture } \\
(\mathrm{mm})\end{array}$ & $\begin{array}{c}\text { Outer } \\
\text { Diam } \\
\text { support }\end{array}$ & $\begin{array}{c}\text { Overall } \\
\text { Length } \\
(\mathrm{mm})\end{array}$ & $\begin{array}{l}\text { weight } \\
\text { (kg) }\end{array}$ & number & Module & $\begin{array}{c}\text { Nominal } \\
\text { Strength } \\
\mathrm{B}=\mathrm{S} \cdot \mathrm{x}^{\mathrm{n}-1}\end{array}$ & $\begin{array}{l}\text { Current } \\
\text { (A) }\end{array}$ & $\begin{array}{c}\text { Magn. } \\
\text { Length } \\
(\mathrm{mm})\end{array}$ \\
\hline MCDO & Single & 58 & $115 \mathrm{~mm}$ & 110 & 6 & 1232 & $\begin{array}{l}\text { MCD } \\
\text { MCO }\end{array}$ & $\begin{array}{c}1.2 \mathrm{E} 6 \mathrm{~T} / \mathrm{m} 4 \\
8200 \mathrm{~T} / \mathrm{m} 3\end{array}$ & $\begin{array}{l}550 \\
100\end{array}$ & 66 \\
\hline MCS & Single & 58 & $120 \mathrm{~mm}$ & 160 & 10 & 2464 & MCS & $1630 \mathrm{~T} / \mathrm{m} 2$ & 550 & 110 \\
\hline $\mathrm{MO}$ & Twin & 56 & $514 \mathrm{~mm}$ & 380 & 250 & $168 \times 2$ & MOM & $6.3 \mathrm{E} 4 \mathrm{~T} / \mathrm{m} 3$ & 550 & 320 \\
\hline $\begin{array}{l}\text { MQT } \\
\text { MQS }\end{array}$ & Twin & 56 & $514 \mathrm{~mm}$ & 380 & 250 & $\begin{array}{c}160 \times 2 \\
32 * 2\end{array}$ & $\begin{array}{l}\text { MQTM } \\
\text { MQSM }\end{array}$ & $123 \mathrm{~T} / \mathrm{m}$ & 550 & 320 \\
\hline MSCB & Twin & $2 \times 56$ & $450 \mathrm{~mm}$ & 1260 & 900 & $376 \times 4$ & $\begin{array}{c}\text { MSM } \\
\text { MCBM }\end{array}$ & $\begin{array}{c}4430 \mathrm{~T} / \mathrm{m} 2 \\
2.9 \mathrm{~T}\end{array}$ & $\begin{array}{c}550 \\
55\end{array}$ & $\begin{array}{l}369 \\
647\end{array}$ \\
\hline MQTL & Twin & $2 \times 56$ & $450 \mathrm{~mm}$ & 1400 & 1850 & $60 \times 2$ & MQTL & $129 \mathrm{~T} / \mathrm{m}$ & 550 & 1300 \\
\hline MCBC & Twin & $2 \times 56$ & $450 \mathrm{~mm}$ & 1100 & 1200 & $78 \times 2$ & MCBCM & $3.1 \mathrm{~T}$ & 100 & 904 \\
\hline MCBY & Twin & $2 \times 70$ & $450 \mathrm{~mm}$ & 1100 & 1200 & $44 \times 2$ & MCBYM & $2.5 \mathrm{~T}$ at $4.5 \mathrm{~K}$ & 72 & 899 \\
\hline $\operatorname{MCBX}(\mathrm{A})$ & Single & 90 & $350 \mathrm{~mm}$ & 700 & 400 & 27 & $\begin{array}{l}\text { MCBXV } \\
\text { MCBXH }\end{array}$ & $\begin{array}{l}3.26 \mathrm{~T} \\
3.35 \mathrm{~T}\end{array}$ & $\begin{array}{l}550 \\
550\end{array}$ & $\begin{array}{l}480 \\
450\end{array}$ \\
\hline MCSTX & Single & 70 & $89.5 \mathrm{~mm}$ & 700 & 4 & 9 & $\begin{array}{l}\text { MCSX } \\
\text { MCTX }\end{array}$ & $\begin{array}{c}52 \mathrm{~T} / \mathrm{m} 2 \\
7.22 \mathrm{E} 6 \mathrm{~T} / \mathrm{m} 5\end{array}$ & $\begin{array}{l}50 \\
80\end{array}$ & $\begin{array}{l}576 \\
615\end{array}$ \\
\hline MQSX & Single & 70 & $380 \mathrm{~mm}$ & 300 & 50 & 9 & MQSX & $80.2 \mathrm{~T} / \mathrm{m}$ & 550 & 223 \\
\hline MCSOX & Single & 70 & $380 \mathrm{~mm}$ & 175 & 30 & 9 & $\begin{array}{c}\text { MCOSX } \\
\text { MCOX } \\
\text { MCSSX }\end{array}$ & $\begin{array}{c}9666 \mathrm{~T} / \mathrm{m} 3 \\
9229 \mathrm{~T} / \mathrm{m} 3 \\
377 \mathrm{~T} / \mathrm{m} 2\end{array}$ & $\begin{array}{l}100 \\
100 \\
100\end{array}$ & $\begin{array}{l}138 \\
137 \\
132\end{array}$ \\
\hline
\end{tabular}

- Multipole correctors sometimes referred to as spool pieces, correct the field quality of a given magnet, in particular the main dipoles.

- Orbit correctors adjust the orbit of the machine, both in the horizontal and vertical plane

- Lattice Correctors adjust functions like the tune and chromaticity of the machine.

A summary of the corrector magnet types and their functions are given in Table I and a summary of important corrector parameters are given in Table II. The correctors range from dipole to dodecapole, with the smallest corrector having a length of approximately $15 \mathrm{~cm}$ and weighing about $4 \mathrm{~kg}$ while the largest is about $1.5 \mathrm{~m}$ long and weighs close to 2 tonnes. They operate at nominal currents ranging from $50 \mathrm{~A}$ to $550 \mathrm{~A}$, main fields vary between $0.03 \mathrm{~T}$ and $3.3 \mathrm{~T}$. The correctors are superconducting, using NbTi conductor (Table III), and although a few will operate in normal liquid helium at $4.3 \mathrm{~K}$ most will operate in superfluid helium at $1.9 \mathrm{~K}$. Further details of most corrector types can be found in [6]-[13].

With the exception of the MCSTX sextupole/dodecapole which is made at CERN, all the correctors are manufactured by European or Indian companies, with whom a total of 10 contracts have been placed worth $~ 50$ MCHF.

\section{ORGANIZATION OF THE PRODUCTION}

For each magnet type CERN supplies drawings sufficient to define the magnetic and mechanical design of the magnets (including end-spacer machining files for dipole correctors) and specifies the materials and construction methods. CERN supplies the superconducting wire and in some cases also yoke laminations and steel for magnet support structures. CERN also supplies equipment to each company for measurement of magnetic field at room temperature and for data acquisition during cryogenic magnet training tests.

The manufacturers are responsible for the creation of all fabrication drawings, design and procurement of tooling, procure-
TABLE III

MAIN PARAMETERS OF THE CORRECTOR MAGNet SUPERCONDUCTING STRANDS

\begin{tabular}{|c|c|c|c|c|}
\hline & Type 1 & Type 2 & Type 3 & Type 4 \\
\hline Overall dimensions $(\mathrm{mm})$ & $\varnothing$ & $0.38 \times$ & $0.73 \times$ & $0.97 \times$ \\
\hline (insulated) & 0.435 & 0.73 & 1.25 & 1.65 \\
\hline \multirow[t]{2}{*}{ Metal dimensions $(\mathrm{mm})$} & $\varnothing$ & $0.32 \times$ & $0.61 \times$ & $0.85 \times$ \\
\hline & 0.375 & 0.67 & 1.13 & 1.53 \\
\hline Insulation Thickness (mm) & 0.03 & 0.03 & 0.06 & 0.06 \\
\hline \multicolumn{5}{|l|}{ Critical current at $4.2 \mathrm{~K}, 5 \mathrm{~T}$ (A) } \\
\hline Perpendicular to wire axis & $>55$ & & & \\
\hline Perpendicular to broad face & & $>100$ & $>630$ & $>1190$ \\
\hline Parallel to broad face & & $>110$ & $>700$ & $>1320$ \\
\hline Copper Matrix RRR & $>100$ & & & \\
\hline $\mathrm{Cu} / \mathrm{Sc}$ volume ratio & $4.0-4.8$ & $4.0-4.8$ & $1.6-1.9$ & $1.6-1.9$ \\
\hline Superconductor & \multicolumn{4}{|c|}{ NbTi with $\mathrm{Ti}=47.0 \%$ by weight } \\
\hline High voltage insulation $(\mathrm{V})$ & \multicolumn{4}{|c|}{1000} \\
\hline Insulation material & \multicolumn{4}{|c|}{ PVA enamel } \\
\hline
\end{tabular}

ment of all components not supplied by CERN, fabrication and testing of the magnets, and quality assurance (including supplying test results to CERN in the form of electronic travellers).

In particular, the manufacturers have to guarantee the performance of the magnet as concerns quenching. A pre-series is defined where the training and retraining performance of the magnets is qualified. In addition, the manufacturer has to verify the magnetic field quality of the magnet.

\section{A. Testing at the Manufacturer}

For each magnet the manufacturers are required to make various mechanical measurements at different stages of construction in order to verify the dimensions of components and assemblies and to check that the magnet has the correct pre-stress at room temperature. In addition they must train the magnets at $4.3 \mathrm{~K}$, measure the magnetic field at room temperature and also make various electrical checks both at $4.3 \mathrm{~K}$ and room temperature to verify the integrity of internal connections and to look for short circuits, both internal and to ground. The magnetic field measurements serve to verify the strength of the main harmonic 
TABLE IV

CORRECTOR MAGNET MANUFACTURERS

\begin{tabular}{|c|c|c|c|c|}
\hline $\begin{array}{l}\text { Magnet } \\
\text { Type }\end{array}$ & $\begin{array}{l}\text { Number } \\
\text { ordered }\end{array}$ & $\begin{array}{c}\text { Number } \\
\text { of } \\
\text { subtypes }\end{array}$ & Manufacturer & Location \\
\hline \multirow[t]{2}{*}{ MCS } & 1232 & 1 & Antec & Bilbao, Spain \\
\hline & 1262 & 1 & KECL & Bangalore, India \\
\hline \multirow[t]{3}{*}{ MCDO } & 616 & 1 & Tesla Engineering & Lancing, UK \\
\hline & 616 & 1 & Crompton Greaves & Bhopal, India \\
\hline & & & MCO inserts CAT & Indore, India \\
\hline $\mathrm{MO}$ & 368 & 1 & Antec & Bilbao, Spain \\
\hline MQT & 160 & 1 & Ansaldo & Genoa, Italy \\
\hline MQS & 40 & 1 & Ansaldo & Genoa, Italy \\
\hline MSCB & 376 & 4 & Tesla Engineering & Lancing, UK \\
\hline MQTL & 56 & 2 & Ansaldo & Genoa, Italy \\
\hline $\mathrm{MCBC}$ & 78 & 4 & Tesla Engineering & Lancing, UK \\
\hline MCBY & 44 & 2 & Tesla Engineering & Lancing, UK \\
\hline MCBX & 33 & 2 & Sigmaphi & Vannes, France \\
\hline $\begin{array}{l}\text { MQSX, } \\
\text { MCSOX }\end{array}$ & 9 & 1 & Ansaldo & Genoa, Italy \\
\hline MCSTX & 9 & 1 & CERN & Geneva, CH \\
\hline $\begin{array}{l}\text { Super- } \\
\text { conductor }\end{array}$ & & & Alstom & Belfort, France \\
\hline
\end{tabular}

and the position of the magnetic axis of the corrector. Should the field harmonics contain unexpectedly high components this indicates that the manufacturing tolerances have not been respected and inverse-field calculations can be made to find the source of the error. For each contract a number of magnets at the beginning of the production are defined as pre-series magnets. These magnets are re-trained at $4.3 \mathrm{~K}$ by the manufacturer after initial training and thermal cycling to room temperature.

\section{B. Testing at CERN}

At CERN, the pre-series magnets undergo visual inspection, re-training tests at $4.3 \mathrm{~K}$ and $1.9 \mathrm{~K}$ and magnetic field measurements at room temperature (to verify correct operation of the measurement equipment used by the manufacturer) and $1.9 \mathrm{~K}$ (to measure hysteresis and saturation). For each contract, it is also planned to select a certain percentage of magnets at random to undergo the same tests at CERN as the pre-series. However, this is proving difficult due to the high load already placed on the out testing resources.

\section{Production Status}

\section{A. Main Dipole Correctors (Spool Pieces)}

Both the MCS and the MCDO production have been split, with contracts for equal numbers of magnets placed in Europe and India in each case (Table IV). The contracts placed in India are followed by the Centre for Advanced Technology in Indore, who are responsible for quality assurance and testing of the magnets. These contracts are all in the series production phase with magnet deliveries on average at the required rate (Table V) with the exception of the European MCDO, which has been delayed largely due to the concentration of effort by both the manufacturer and CERN into other contracts placed with the same
TABLE V

CORRECTOR MAGNET PRODUCTION STATUS

\begin{tabular}{|c|c|c|c|c|}
\hline $\begin{array}{l}\text { Magnet } \\
\text { Type }\end{array}$ & Manufacturer & $\begin{array}{l}\text { Percentage } \\
\text { Completed }\end{array}$ & At full rate? & Remark \\
\hline \multirow[t]{2}{*}{ MCS } & Antec & $60 \%$ & Yes & \\
\hline & KECL & $40 \%$ & Yes & \\
\hline \multirow[t]{2}{*}{ MCDO } & Tesla & $1.5 \%$ & No & \\
\hline & Indian & $42 \%$ & Yes & \\
\hline MO & Antec & $33 \%$ & Almost & \\
\hline MQT & Ansaldo & $2 \%$ & No & Near Critical \\
\hline MQS & Ansaldo & $3 \%$ & No & \\
\hline MSCB & $\begin{array}{l}\text { Tesla } \\
\text { Engineering }\end{array}$ & $5.5 \%$ & No & Critical \\
\hline MQTL & Ansaldo & $0 \%$ & No & \\
\hline МCBC & $\begin{array}{l}\text { Tesla } \\
\text { Engineering }\end{array}$ & $2 \%$ & No & Critical \\
\hline MCBY & $\begin{array}{l}\text { Tesla } \\
\text { Engineering }\end{array}$ & $0 \%$ & No & \\
\hline MCBX & Sigmaphi & $33 \%$ & Yes & \\
\hline $\begin{array}{l}\text { MQSX, } \\
\text { MCSOX }\end{array}$ & Ansaldo & $80 \%$ * & Yes & \\
\hline MCSTX & CERN & $40 \%$ & Yes & Testing late \\
\hline $\begin{array}{l}\text { Super } \\
\text { conductor }\end{array}$ & Alstom & $100 \%$ & & $\begin{array}{l}\text { Winding } \\
\text { losses will } \\
\text { require more }\end{array}$ \\
\hline
\end{tabular}

manufacturer. Small problems are frequently found in the magnets delivered to CERN, minor in the sense that they are repairable but they do need to be repaired before they can be used in the LHC. Consequently every magnet produced needs to be inspected by qualified CERN personnel before it is delivered to a cold mass assembler.

\section{B. Short Straight Section (SSS) Correctors}

These correctors are single-sourced, with a single European manufacturer for each type. The MO is in full production with regular deliveries of 8 magnets/month, this rate is expected to reach the required 10 magnets/month by the end of 2003. MQT and MQS are combined into a single contract, pre-series testing should be complete by the end of October 2003. Four pre-series units have already been tested successfully at CERN, and approval has been given for series production to begin without waiting for the test results of the remaining two pre-series units. This contract has been delayed by problems with the manufacturers' cold testing equipment (now apparently solved) and cold testing will be the bottleneck to be overcome in order to reach the required 10 magnet/month production rate: the planned rate of two tests/month will be sufficient only to supply 8 magnets/month, a way will therefore need to be found to increase the testing rate. Delays in the MSCB contract have meant that magnets have been delivered directly to the cold mass assembler without undergoing testing at CERN (only one magnet has been tested at CERN). MSCB production was stopped this summer for 2 months because of dipole module retraining problems, related to insufficient prestress due to various causes, but is now ramping up again.

\section{Insertion Region/Dispersion Suppressor/Inner Triplet Correctors}

The first MQTL magnets are expected to arrive at CERN in early 2004. They are part of the same contract as MQT/MQS 
and the same manufacturer also has the contract for the MQSX and MCSOX, which means there is a competition for resources between these magnet types. The manufacturer has so far concentrated on MQT since it is easier to make than the MQTL, which is 4 times longer. In order to cut the tooling development time for MQTL, CERN is in the process of fabricating winding and impregnation tooling for MQTL coils which will be loaned to the manufacturer for this contract.

The MCBC/MCBY contract has been placed with the same company who make MSCB, and has been delayed since most attention has been placed on MSCB. A first MCBC has recently arrived at CERN.

All MCBX magnets are trained and magnetically measured at CERN and not by the manufacturer. The first MCBX magnet was destroyed in testing at CERN, leading to a change to vacuum impregnation for the coils. The first 8 magnets of the new design have recently been tested at CERN, with adequate results.

The first MQSXA had been delivered to CERN. Due to a recent design change by the beam physicists' the magnet was split in skew quadrupole and nested multipole parts, MQSX and MCSOX. Production of this small series should be complete by the end of the year.

Production of MCSTX insert coils is well underway at CERN, and first tests inside a MCBX are now underway.

\section{CONCLUSION}

A number of contracts are still in the start-up phase, meaning that the manufacturers' require a great deal of technical support from CERN. At the same time, those contracts that are in production require close attention from CERN in order to ensure that the required quality levels are maintained. Many Contracts have had important delays of at least a year or more. Reasons seem to be:

- Some firms were inexperienced making superconducting magnets and it took much longer than they expected to make the first working magnets.

- The larger magnets (dipoles) and nested magnets had more training problems than the smaller magnets.

- The cable ribbon is not easy to produce, and led to repairs in the coils.

- Cryogenic testing is a bottleneck, which slowed down the production when retraining problems occured.

As more and more magnets begin to be produced, the administrative workload (travelertravellers, data analysis,...) is increasing rapidly. The warm magnetic measurement benches used by the manufacturers need close follow-up. The time needed to provide feedback to manufacturers about any problems found is often long, so that many magnets need to undergo corrective action once a problem is detected.

The level of experienced manpower available at CERN to tackle these issues is currently limited. Therefore the successful completion of the corrector procurement will require more resources than presently available.

\section{ACKNOWLEDGMENT}

The authors are particularly grateful for the very fruitful and expert collaboration of our Indian colleagues at CAT.

\section{REFERENCES}

[1] M. Allitt, A. Hilaire, A. Ijspeert, M. Karppinen, J. Mazet, J. Pérez, J. Salminen, M. Karmarkar, and A. Puntambekar, "Principles Developed for the Construction of the High Performance, Low-Cost Superconducting LHC Corrector Magnets," CERN, Geneva, LHC-Project-Report-528, Mar. 6, 2002.

[2] J. Salminen and A. Ijspeert, "Experience With Different Constructions of Superconducting Corrector Magnets for the LHC," CERN, Geneva, LHC-Project-Report-254, Nov. 11, 1998.

[3] A. Ijspeert and J. Salminen, "Superconducting coil compression by scissor laminations," in EPAC-96, Sitges, Spain, Jun. 1996.

[4] A. Hilaire, A. Ijspeert, and J. C. Pérez, "Simulation of the Effect of a Series of Superconducting Magnets on a Quenching Magnet Using a Controlled Current Pulse," CERN, Geneva, LHC-Project-Report-527, Mar. 6, 2002.

[5] R. Schmidt, C. Giloux, A. Hilaire, A. Ijspeert, F. Rodríguez-Mateos, and F. Sonnemann, "Protection of the Superconducting Corrector Magnets for the LHC," CERN, Geneva, LHC-Project-Report-419, Sep. 23, 2000.

[6] Z. Ang et al., "Further development of the sextupole dipole corrector (MSCB) magnet for the LHC," IEEE Trans. Appl. Supercond., vol. 10, no. 1 , pp. 158-161, March 2000.

[7] M. Allitt et al., "Further development of the sextupole and decapole spool corrector magnets for the LHC," IEEE Trans. Appl. Supercond., vol. 10, no. 1, pp. 162-165, March 2000.

[8] J. Salminen et al., "Experience With the Fabrication and Testing of the Sextupole Superconducting Corrector Magnets for the LHC," CERN, Geneva, LHC-Project-Report-263, Feb. 2, 1999.

[9] M. Allitt et al., "Development of Superconducting Tuning Quadrupole Corrector (MQT) Prototypes for the LHC," CERN, Geneva, LHC-Project-Report-531, Mar. 6, 2002.

[10] M. Bajko et al., "Training Tests on Single Superconducting Coils of Sextupolar Correctors for LHC," CERN, Geneva, LHC-Project-Report-264, Feb. 3, 1999.

[11] M. Karppinen, A. Ijspeert, N. Hauge, and B. R. Nielsen, "The Development of the Inner Triplet Dipole Corrector (MCBX) for LHC," CERN, Geneva, LHC-Project-Report-265, Feb. 3, 1999.

[12] Z. Ang et al., "Magnetic Performance of First Low-Beta Dipole Corrector Prototype, MCBX," CERN, Geneva, LHC-Project-Report-237, Sep. 25, 1998.

[13] M. Karppinen, J. C. Pérez, and R. Senis, "Inner triplet corrector package MQSXA for the LHC," IEEE Trans. Appl. Supercond., vol. 12, no. 1, pp. 102-106, March 2002.

[14] A. Ijspeert and J. Salminen, "Superconducting Coil Compression by Scissor Laminations," CERN, Geneva, LHC-Project-Report-237, Sep. 25, 1998 . 